\title{
Formation of tools of resource providing management at the enterprise of the industry of construction materials in modern conditions
}

\author{
Natalia Verstina, ${ }^{1, *}$ \\ ${ }^{1}$ Moscow State University of Civil Engineering, Yaroslavskoe shosse, 26, Moscow, 129337, Russia
}

\begin{abstract}
The retrospective analysis of the results of activities at the level of industrial sector of the Russian economy in general and at the level of certain subjects of economy - the enterprise of construction materials and products is completed in the article. According to the analysis results the insufficient efficiency of the use of cumulative resource capacity of the enterprises is proved and the need of the development of complex tools of resource providing management, to which the priority attention is caused by the crisis of economy requiring taking measures to diversification of a range of construction materials and products of the construction offered by the enterprise for the markets, is determined. In the core of the offered tools of management there are approaches of "ramp-up" of the management directed to the maximum concentration of resources of the enterprise in case of new products launch for the construction industry. Three options of financing of production, based on the choice of a ratio of loan and own sources of means are considered. Some conditions of macroeconomic nature, which are important for effective development of the enterprises involved in production of construction materials and products are determined in the conclusion.
\end{abstract}

\section{Introduction}

Modern construction, as well as other branches of the national economics is developing on the basis of the state level priorities which are presented in the Russian Federation by the programme documents, accepted for the long-term outlook and assuming participation of all the subjects of the respective sphere of economic activity in their performance.

At the same time, during accomplishment of effective objectives and tasks in the construction sphere there are essential changes in the economic situation, the crisis, which has been observed for the last four years in the scales of world economy, is among them. The reference points, which have key value for construction are provided in numerous documents and they are determined on the basis of the forecast of social and economic development till 2035, prepared by the Ministry of Economic Development according to

* Corresponding author: verstina@mail.ru 
which the economy of the Russian Federation, as well as other developed countries, will overcome crisis consequences the next 20 years. [1-19]

The exit of the Russian Federation from the recession in 2017 will be followed by slow growth: on average for $2 \%$ a year (from 1.7 to at most 2.6\%). It is intended to increase GDP of the country for forecast 20 years only by 1.5 times. Real incomes of the population will grow on average for $1.4 \%$ a year and will come to the level of 2013 only in 2021 . For construction and industries, adjacent to it, that means that there will be a few investment resources and on this background the types of construction products, effective for the consumer, based on progressive constructive decisions will be demanded.

At the same time it is obvious that production of the construction materials and products answering to requests of a modern construction shall be performed on the basis of buildingup of resource capacity of their producers and its transformation shall be performed due to application of innovative resource-saving production technologies.

The upgrade of operating enterprises, and also creation of new productions, with updated assortment, optimum price -and-qualities relation for construction materials and products will become the main results of the innovative technologies implementation. At the same time the most important indicator of the use of resources in case of industrial productions, i.e. the power consumption according to the established state priorities will decrease by 2020 almost twice in comparison with the level of 2008 in which the backbone document of the development of economy of the Russian Federation - "The concept of long-term social and economic development of the Russian Federation for the period till 2020" was accepted (further - the Concept).

It is important that the development of production of construction materials and products needs to be performed in the context of the modern trend on rapprochement of standards, developed by producers of developed countries, in particular, the direction of state policy is ensuring harmonization of the Russian technical standards of production with foreign ones to the level of 56.5 percent from their total number.

At the same time, within the performance of the goals and tasks some essential changes can occur and do occur in the economic situation, the crisis, observed within the last three years in scales of world economy is among them. The current 2016 which continues the tendency of the development of the crisis manifestations in the Russian economy proves that the situation of instability proceeds and, besides, it brings rather unpredictable events of economic life, which are directly influencing the resource providing of the industrial enterprises (IE).

The economic situation of 2015 and the forecasts for the next year, is characterized by the considerable uncertainty which has developed because of the difficult geopolitical situation, the existence of inflationary and other impacts of macroeconomic character on the IE. According to the results of 2015 the recession of the Russian economy is at the level of $4 \%$ of GDP, while inflation reached $14 \%$. At the same time experts estimate that only $1.5 \%$ have been caused by the negative external factors.

The main reasons for braking were mainly brought by the internal factors which acted as limiters of the growth and did not allow to the use the available resource potential properly. For this reason the important condition of their activity and performance of strategic reference points is the definition of the instruments of resource providing management of the IE and stable financing of their realization at the level of particular subjects of economy corresponding to the current economic realities $[2,17,18]$.

Obviously, for the IE this situation provides both reference points and new opportunities for the development, and also defines the need of overcoming of a number of negative factors as the important condition of receiving of additional benefits. 


\section{Methods}

As a rule the resource providing of an industrial enterprise was traditionally perceived as a necessary component in the enterprise management system which does not undergo any essential changes neither from the point of view of the management organization, nor from the positions of definition of the economy of these processes. However, the consideration of this question in the retrospective aspect testifies the need of revaluation of the developed approaches for the national economy scales as well as at the level of certain subjects of the economic activity. For the confirmation of this situation the analysis of the efficiency of the use of resources in two aspects was carried out: in general for the industrial sector of economy and for the results of activity of the industrial enterprises. Within the conducted research the answer to the question what becomes the key characteristics of the organizational-and-administrative tools of resource providing management in the modern conditions of the crisis economy was obtained.

During the last 15 years the results of the activity of the industrial sector of the economy of the Russian Federation is characterized by a number of aggregated indicators which demonstrate the cumulative efficiency of the use of the resources attracted by the enterprises. $[3,4,20]$. From our point of view, two indicators are the most interesting: gross value added (GVA) and industrial production index (IPI). For the identification of problem positions in the use of the IE resources which are important for to be overcome on the basis of updating of the management tools both absolute values of these indicators, and their dynamics are rather informative. The important starting point of the research was the fact that one and a half decades ago, in 2002 the Russian industry, having concentrated huge resources the IE, gave the greatest contribution to the GVA production in the national economy $-27.5 \%$. Ten years later in 2012 this indicator made up $29.6 \%$ that were still the maximum contribution of the industrial sector to the GVA production in the Russian economy. Throughout this period the resource potential of the IE provided the greatest value of GVA in $2005(32.7 \%)$, then the decrease in the indicator to a minimum level (27.4\%) was noted in 2009 which "collected" the consequences of the crisis situation of that period in the maximum degree. So far the economic situation was not stabilized, but on the contrary, became more unstable: in 2015 the considerable falling of this indicator to the level of $21 \%$ was noted. The fluctuation of the macroeconomic situation in the scales of all the Russian economy which had already endured the crisis phenomena twice also become the important factor, defining the unstable nature of the noted processes. The main content of the reaction of the industrial sector to the crisis situations was the following: in 1998 the Russian economy reacted with acceleration of the industrial production growth quickly and at the substantial scale, as a result the high rates of GVA of the industrial sector and their growth during the next years were obtained. However, during the recession of 2008-2009 this effect was much more reserved, and it defined the decrease in the share of the industry in GVA at the national economy scales. The fact of the decrease in GVA of the industrial sector of the economy became the important proof of the inefficiency of the crisis response measures in 2014-2015. In 2016 the main indicator of macroeconomics (GDP) will become the continuation of the chain of "take-off" and "falling" of its values within the previous years (Figure 1).

Changes of the share of the industrial production of such character, existing within the instability of the economy in general, proves the system decrease in the return from the resources of the industrial sector as well as the need of the formation of the complex character of decisions which would allow to approach the IE resources in a new foreshortening and to define some possible ways of their efficiency growth. It is possible to refer the change of the model of ensuring economic growth and, first of all, the growth of its industrial sector as one of them. 


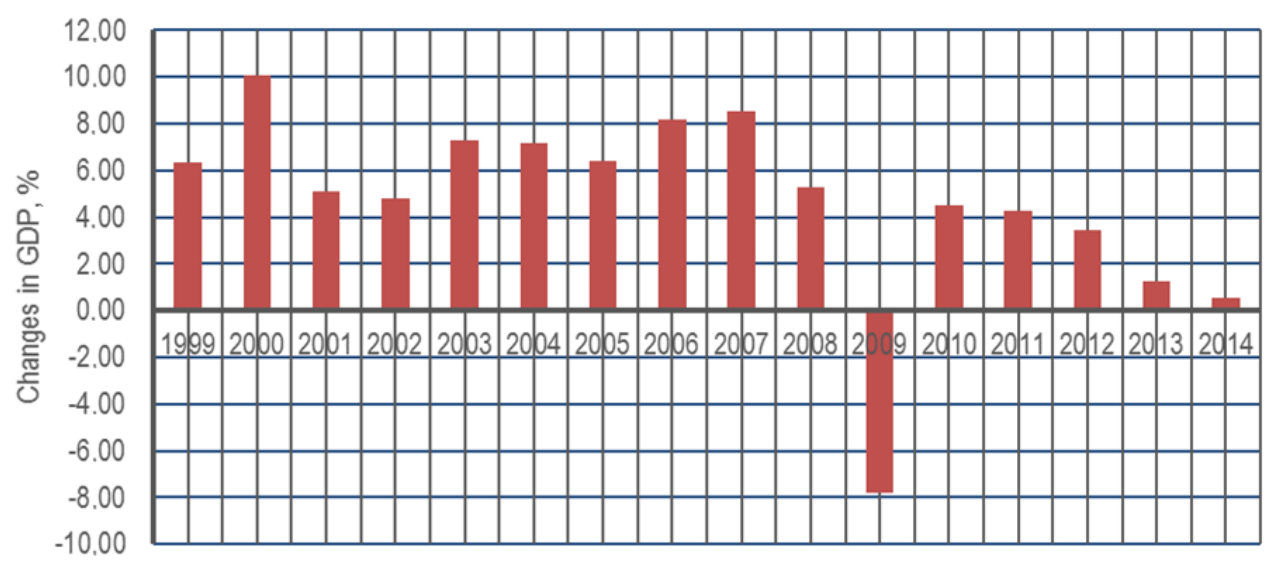

Fig. 1. Rates of gross domestic product growth in the Russian Federation (\% to the previous year) in $1999-2014$.

The effective use of the IE resources as well as the creation of products, demanded by the market, on this basis find their reflection in the growth of the industrial outputs and in the growth in volumes of sales in value terms. Characterizing in general the situation in the Russian Federation we should note that at the beginning of the considered period the dynamics of the IPI growth was small (at the level of several percent), and in 2013 "the decrease point" was found: there was a reduction of its values according to the results of 2013 up to $100.5 \%$ (in 2012 it was $105.1 \%$ ). Statistical data for 2014 confirmed the lack of the significant IPI growth: during the considered period it made up $101.7 \%$ in comparison with the previous year, in 2015 the situation did not improve. During the considered period, the situation of the decrease in the efficiency of the use of resource potential of the IE involved by them into the process of the creation of products was observed in practice, the demand it in the market was falling. In our opinion, two types of factors caused this phenomenon: internal for the IE (such as the exhaustion of the opportunities of traditional approaches to the deduction of positions of the IE in the market, and external (such as the adverse world conditions, promoting the essential deterioration in financial results of the export-oriented kinds of activity. It is obvious that the production diversification, the updating of the products range, taking into account the crisis during rather short time period would be the most rational solution of the use of the saved-up resource potential of the IE in the current conditions.

In the conditions of such a difficult situation in the industrial sector of the economy in general, the analysis was detailed by the consideration of the situation at the level of certain subjects of economic activity - industrial enterprises. The 400 of the largest Russian companies according to the market value of their assets, estimated on the September 1, 2015 included more than 150 industrial enterprises and that is the important argument of the importance of their resource potential for the national economy. The data considered below, detailing the aforesaid aggregated indicators, which allow to concretize the studied perspective, are evident. The balanced financial result of the IE (the difference between the profit made and the losses suffered) which directly defines the efficiency of the use of the resources, attracted by the IE, began to be reduced considerably at all the enterprises of the economy of the Russian Federation since the beginning of 2013 and by the end of the year it made up 6853.75 billion rubles, that is $17.3 \%$ less then in 2012 (in the previous year the growth of $10.8 \%$ took place). It was the beginning of the trend of the decrease in the efficiency of the use of the IE resources, while the analysis demonstrated that since the noted "decrease point" the profit on sales of the IE decreased in comparison with 2012 by 
$11.1 \%$. The indicators, determining the volume of the balanced financial result of the IE proved very ambiguous dynamics and in the subsequent period one can observe the growth of the prime cost and the decrease in the profit, which is the essential factor of financing of actions for the overcoming of the negative phenomena in the conditions of the crisis. Therefore the use of such an approach to management which would be focused on the questions of ensuring financing of the IE activity, undergoing the diversification processes and directed to the overcoming of the crisis phenomena of the economy is very actual in the current conditions.

The more detailed consideration of the question of financing of the IE proved that the developed operating conditions of the industrial enterprises are characterized by the existence of some negative dynamics in the provision with the sources of financial resources both during the implementation of the current activity, and during the implementation of investment projects. It is confirmed by statistical data on the change of coefficients of autonomy and provision with own current assets of the IE, which values made up $40 \%$ and $20.8 \%$ respectively in the end of the third quarter of 2015 . The analysis proved that the borrowed funds become the most widespread source of financing of the production activity of the industrial enterprises. Analytical data confirm the complication of the access to them in the domestic market in 2015-2014 in comparison with previous year 2013: the constant interest rate development on the credits followed by the increased key interest rate of the Central Bank of the Russian Federation as well as the reduction of the possibility of receiving any external financing from the foreign banks, showing the conservative policy of crediting [5,6] is observed. At the same time, the research proved that the measures, taken by the government in this direction, were rather essential: just in 201519.613 billion rubles were directed to the subsidies for compensation of part of expenses on the credits for the systemically important enterprises according to the resolution of the Government of the Russian Federation. Their special-purpose character was expressed: the subsidies are directed to the compensation of the expenses on the credits obtained in the Russian credit institutions, in Vnesheconombank, and in the international financial organizations, created according to international treaties, in which the Russian Federation participates. However, in our opinion, the necessary financing of projects of the IE development in the modern conditions is not the function of the government only, but now it is much more important to make active the capacity of producers in the direction of the creation of some effective tools of the resources management, and first of all - the tools of the financial resources management [7]. As for the resource management summarizing the carried-out analysis, we should note that during the next two years there are no reasons to expect any improvement neither of the IE positions, nor of the general indicators of the industrial sector of economy in the condition of the use of the managerial decisions which were developed earlier and which are outdate today, which did not contain any possibility of the IE promotion in the market despite the crisis conditions.

\section{Result}

It is possible to note that nowadays there are some objective conditions for a certain transformation of the traditional tools of the resource management and for the search of new, more productive tools which would provide desirable efficiency in the conditions of the rigid terms determined by the crisis situation. Relatively recently the "ramp-up" management, focused on its application by the enterprises during the responsible period between the creation of the first sample and production of the customer-oriented products, accented on the logistic requirements of mass production $[8,9]$ entered the range of theoretical developments and practice of management. In the practice of the IE activity, they often overestimate the relation to the available resources in this foreshortening: a 
certain part of those resources is directed to the updating of the product portfolio, to the realizing the policy of diversification. In the organizational aspect of the ramp-up management is harmonious for the solution of the problems of the diversification of the IE production in the crisis situation, but in our opinion it has to be strengthened by some economic tools. From the positions of updating of the tools of the resource management at the IE it is important that ramp-up management is directed to the correct and timely assessment of the existence of resources and to the development of decisions for various situations of updating and expansion of the range of products produced by the IE: before starting of any new seasonal or spontaneous production the increase in sales, rebranding of already known perspective production and other measures should be undertaken. The specifics of the ramp-up tools of management, which was pointed out in this research, assumes the implementation of managerial actions and (in an adverse situation) the combinations of the predicted increase in the demand for production and at the same type the presence of limited quantity of resources at the IE, including financial and temporary resources. The tools of management within the ramp-up management are differentiated through three stages: pre-series production, pilot production, mass production. These stages are directed to the optimization of various elements of the IE production systems, restructuring of the resource providing along with the expansion of production capacities to the level of the planned "production peak". The research conducted earlier proved that at the closing stage of the ramp-up possible some temporary delays depend on the level of innovation of a product and on the characteristics of engineering procedures. [10-18]. Tyre in his research determines the high level of correlation between the duration of ramp-up and the complexity of new technologies, the extent of changing of the system, and also the scale of the project. At the same time, the third stage already means the end of the planned project of the development of a new product production of the IE in the conditions of production diversification. Therefore the time expenditure and the costs of the material resources caused by such features of the project have to be provided earlier, during the preinvestment calculations. At the stage of mass production the organization of uninterrupted financing of the acquired material resources which used leaned only on the classical tools of working capital management of so far is important.

The new economic tools of management at the stage of mass production, offered to consideration, are based on the achievement of the required level of financing of the production activity taking into account the structure of sources of financing. Estimation of cost and volumes of borrowed funds is especially actual in the crisis situation when the IE have to be seriously maneuvered regarding the financial resources, attracted for the projects of diversification, often carrying out the mode of "manual control" of management in this activity. It allows to speak about obtaining the tool of the resource providing management, which was not used earlier and which is connected with the regulation of the structure of sources of financing in the conditions of mass production which provides stability of the achieved results on launching any new product into the market. This tool is found to be complex, as it can be used in various conditions of implementation of the third stage of the ramp-up and beyond its limits: at reaching the design capacity of a new product, during production of a product in the volume of design capacity, during increasing production due to attraction of additional financial resources according to the market requirements. The features of application and analytical dependences of the complex tools of the resource providing management at the IE according to the three aforesaid options of promotion of the launched products in the direction from the initial offer in the market to the situation of increase in demand for it and the need to increase in resources of the enterprise for performance of this task (Table 1) are presented in the table below. 
Table 1. Options of promotion of the launched product of the IE on the third ramp-up stage and after it.

Formalization of the criterion of the management tool used
Model for decision-making on the capital structure

The initial offer of the product launched into the market (the third ramp-up stage, the organization of mass production)

$R_{s}(z)=\frac{(B(z)-C(z)-K(z)) \cdot(1-n)}{C_{s 0}+C C}$
$\rightarrow \max$

where $B(z)$ - sales proceeds;

$C(z)$ - full production expenses;

$K(z)$ - sum of percent for the credit;

$n$ - profit tax rate;

$C_{s 0}$ - volume of own working capital;

$z$ - share of borrowed funds in the general structure

of sources of the working capital. $z^{*}=1-\sqrt{1-z_{o}+\frac{1}{b} \cdot\left(1+k_{o}-\frac{P}{c}\right)}$,

where $z^{*}$-optimum share of borrowed

funds;

$k_{0}$ - minimum interest rate at some $\mathrm{z} 0$;

$z_{0}$ - initial share of borrowed funds in the

general structure of sources of working

capital;

$c$-specific production expenses;

$b$ - coefficient of growth of the interest rate

for the credit at $1 \%$ growth of $\mathrm{z}$.

The organization of production of the product which has been already launched into the market (after the third ramp-up stage, mass production)

$R_{s}(z)=\frac{(B(z)-C-C C-K(z)) \cdot(1-n)}{C_{s}(z)+C C}$
$\rightarrow \max$

where $C$ - required volume of working capital;

$C C$ - the volume of constant expenses (it is provided

at the expense of own funds);

$C_{s}(z)$ - volume of own working capital.

Increase in demand for the product which is already launched and produced constantly (after the third ramp-up stage and after finishing the project of the organization of mass production)

The core of the offered tools is the definition of the share of borrowed funds in the structure of sources of the working capital, which will maximize the value of profitability of own capital (Rs $\rightarrow$ max), characterizing the volume of the cumulative resources of the enterprise. At the same time the cost of attraction of sources of the working capital is considered. It is, in turn, influenced by external factors (base rate of Central bank, market conditions of the capital, terms of short-term crediting, etc.), and by internal factors as well (features of production, level of loading of capacities, a financial condition of the enterprise, etc.). Therefore making managerial decision in any of the options characterized in the table \#1 represents a multiple-factor optimizing task. For that purpose the research includes the formalization of the elements of the general costs of resources (Cgen) and income (I) in the form of functions of the share of borrowed funds in the structure of 
sources of formation of working capital (z) taking into account several limiting conditions determined by the specifics of the stage of mass production of the product launched into the market. The conditions are the following: attraction of financial resources happens in the short-term temporary period of activity of the IE, the missed benefit from the made decisions is small and we do not consider it, a source of own means (Cs) are the retained earnings, a source of loan $(\mathrm{Cz})$ is the loan granted to the IE, the price of realization of the launched products (P) and specific production expenses (c) are fixed in time. At the same time it was considered that for the organization of financing of the acquired material resources in the conditions of unstable market condition of sale in the crisis situation, the standard approach to the representation of the working capital in the form is used. The working capital is represented as two components: the main and variable which, in turn, can be created from own $(\mathrm{Cs})$ and (or) borrowed funds $(\mathrm{Cz})$ (taking into account costs of their attraction) in different ratios. For the search of the maximum of function of own capital profitability of the IE characterizing the volume of cumulative resources of the enterprise, the differentiation method presents the analytical ratios defining the share of borrowed funds in the structure of sources of the IE for each of the option the working capital (Table 1).

We will note the features of the use of the complex tools for each of the options of promoting of the launched products of the IE. As for the first option, as a rule, in the situation of crisis there are no enough own financial sources, borrowed funds are raised for financing activity, there is a problem of the maximum decrease in expenses in general for the enterprise. Therefore additional attraction of borrowed financial means to be carried out at the minimum cost, in the required volume and for the minimum terms. The determined parameters have to be connected with the planned increase in the sales proceeds for the new product up to the greatest possible size, as it is provided in the analytical dependences. The obtained analytical ratio of the share of borrowed funds (Tab. 1) demonstrates that its volume is at the same time influenced by several economic parameters of activity, and this influence has difficult structure. It should be noted that one of the factors is the initial share of the borrowed funds $(\mathrm{z} 0)$ which also exerts impact on the interest rate for attraction of the credit.

As for the second option, the minimization of expenses including expenses on the replenishment of the working capital demanded for production remains the main problem of financing of the production of the launched product which is already bringing in the income also. Therefore, having recorded the size of the income and the volume of the current assets demanded for it, the condition of financing of the constant component of production costs from own funds allocated for these purposes in priority we can speak on the basis of analytical dependences (Tab. 1) about the influence of the interest rate, initial a share of borrowed funds, and also volume and price of realization of the made production on the optimum volume of the share of borrowed funds in the structure of sources of the working capital. At the same time in the regard of the integrated specific indicators it becomes possible to define the required structure of the sources of formation of the working capital depending on the operating production conditions.

As for the third option, obtaining the additional income from increase of the demand for the launched products is possible, but at the same time the increase in volume of the used current assets at the expense of own and borrowed sources is also required. Their volumes vary and they are independent from each other, each of them exerts various impact on the indicators of activity of the enterprise. Analytical dependence (Table 1) demonstrates that the optimum changes of volumes of own and borrowed funds are in interrelation. When making a managerial decision on the formation of sources of the working capital it is necessary to consider that after the end of the third stage of the ramp-up management and after stabilization of output of the launched product, within the production growth, there is 
a favorable optimum growth of borrowed funds for each growth of own funds of the IE $[12,13]$.

In practice it is important for the IE, which are developing projects of new production, to use the offered tools of the resource providing management not only at the level of making managerial decisions, but also at the level of tactical management - by drawing up budgets of cash flow, during the production stocks taking into account the expenses connected with attraction of borrowed sources of financing and the chosen the structure of sources of the working capital and also in the strategic aspect being guided by the purpose of ensuring growth of cost of the enterprise [14-16].

\section{Discussion}

It is obvious that the use of complex tools of the financial resources management demands separate consideration and also demands the fact that the use of own funds for the formation of working capital is not free. It is necessary to define the missed benefit from the investment of the own funds in the alternative way: into deposits or by sending them to any commercial turnover. Being in a commercial turnover (in the deposit) own funds of the IE (Cs) make $r \%$ of profit from each invested ruble per the unit of time. The total amount of the income for the accepted short-term time period will make rCs rubles. Upon the withdrawal of $\mathrm{Cs}$ from this turnover for investing it in the working capital and coverings costs of production, the alternative income rCs will take the form of additional expenses (expenses of the missed benefit). The full variable expenses formed from own and borrowed sources of the working capital taking into account the missed benefit will make:

$$
C=C V=C V_{0}+\Delta C V+K(z)=C_{S}+r \cdot C_{S}+C_{z}+k(z) \cdot C_{z}=C_{S} \cdot(1+r)+C_{z}(1+k(z))
$$

Where $\mathrm{k}(\mathrm{z})$ - the interest rate for the credit (depending on the borrowed to own funds ratio);

$\Delta C V=C_{S}+C_{z}-$ sum of additional resources for the replenishment of working capital;

$K(z)=k(z) \cdot C_{z}-$ sum of percent for the credit.

Four possible options of a ratio of profitability of alternative investments and cost of the credit were revealed:

1. $\mathrm{r}<<\mathrm{k}(\mathrm{z})$ - the missed benefit is small (much less than the interest rate for the credit) therefore the related additional expenses of $\mathrm{g}(\mathrm{z})$ can be neglected. This situation was also considered earlier for the optimized structure of sources of the formation of the working capital.

2. $r>k(z)$ - if the rate of return of the alternative use of own capital exceeds the interest rate for the credit (i.e. the missed benefit is rather big), then it is favorable for the IE to launch a new product exclusively "on credit" even in the presence of the sufficient sum of its own capital (it is inexpedient to take it from any other turnover in this case).

3. $r \approx k(z)$ - there is the need of optimization of the share of borrowed funds;

4. $\mathrm{r}<\mathrm{k}(\mathrm{z})$ - the credit at high interest is not favorable, but the possible volume of own funds can be limited by $\mathrm{Cs} \leq \mathrm{Csmax}$. Respectively, the attraction of the credit is not excluded.

The analysis of possible alternative ways of the investment of own fund of the IE in the situation of crisis demonstrates that the most characteristic of them is the ratio when standard of the missed benefit (deposit rate) is below the interest rate for attraction of borrowed financing $(\mathrm{r}<\mathrm{k} 0)$. 
Having accepted the assessment of the expenses of the missed benefit and taking into account the financial result obtained by the time of receiving profit (with the assumption of duration of the considered short-term period of the investment of own funds to be single, while the financial result of the IE activity is assumed to be obtained once, and the settlement formula is added with the size $g(z)$, we will receive the specified ratio for the calculation of profitability of the own capital:

$$
R_{S}(z)=\frac{B-C \cdot(1+r)-C C-g(z)}{C_{S}+C C},
$$

Where In - sales proceeds of the maximum volume of production at Qmax - const, at the price of realization $\mathrm{P}$. The optimum share of borrowed funds $(\mathrm{z} *)$ in the structure of sources of the working capital defined from the condition is calculated on the following formula:

$$
z^{*}=1-\sqrt{1-z_{0}+\frac{1}{b} \cdot\left(k_{0}+1\right)-\frac{P \cdot Q}{b \cdot C_{0} \cdot(1+r)}} .
$$

The volume of the optimum share of borrowed funds will be defined by the ratio of coefficients of growth of the interest rate and the standard of the missed benefit. The received ratio for the definition of the share of borrowed funds in the structure of sources of formation of the working capital demonstrates that the existence of expenses of the missed benefit from the investment of own funds into formation of the working capital displaces the structure of sources towards a bigger attraction of borrowed funds within the condition of the use of complex tools of the financial resources management at the IE.

The complex tools of the resource providing management at the IE in the situation of crisis of the economy have also the restrictions, which are caused by the macroeconomic situation. According to Strategy Partners Group, the Russian market now and in the long term of 10-20 years will make no more than $1-3 \%$ of the world market on the majority of positions. For this reason many projects of the launch of new products, even those developed by large IE can pay off only in the conditions of the offer of any competitive products in the global markets due to the use of the scale effect. The constraining condition which is complicating the policy of diversification in the situation of crisis is the chronic lack of the investment resources in the domestic economy. This conclusion is proved by the organization of financing of the IE development considered above which is influenced in the macroeconomic aspect by two main conditions: - tax burden and availability of credit resources. Nowadays the tax burden in the Russian Federation makes up about 54\% of the IE income. It is significantly higher, than that in many countries with stable economy, and also developing states. Nowadays in the conditions of sharp jump of the main currencies in the Russian Federation it is important not only to create the preferential tax regime for investors, but also to change the government opinion to the tax concessions per se. Considering the official statements about the complication of the economic situation in the beginning of 2016, the reduction of budgetary funds for financing of the current problems of social-and-economic development of the Russian Federation, the tax concessions for the from IE investors on the projects of diversification and launch of new products - it is no other than the state investment in the increase in future taxable basis.

In general only about $10 \%$ of investments of the Russian IE are financed by banks. According to the World bank, the volume of the credits of different types issued to the private sector of the economy of Russia makes up about $47 \%$ of GDP today. The expansion of the involvement into the financial turnover of such types of the IE resources as personal goods, earth, intellectual property, and also the elimination of imperfection of the domestic 
legislation regulating transactions on financing of certain assets of the IE by the means of issue of securities (securitization) as well as by the means of operative leasing can become an important condition of the use of financial resources of banks for the diversification. Fixing in the industrial policy of regional authorities, and also fixing at the federal level of the principles which are providing the simplification of access to cheap and long-term external financing of investments of the enterprises has to act as a backbone condition of providing the IE resources, sufficient for the increase of the efficiency of their use, in our opinion. In particular, granting the state guarantees on the investment credits, refinancing of the investment credits in the development Banks, available system of subsidizing of interest rates can be mentioned.

Considering the functional aspects of the policy of diversification at the IE, we can point out two main discussed models of its realization, depending on the fact what is chosen as the main link at a stage of its development and who plays the key role in the goal-setting, preparation of projects and measures, definition of the conditions of realization and the assessment of efficiency. The first of them consists in the need of ensuring by the state large-scale investments for the purpose of the complex solution of the problems of import substitution on the basis of innovative development. In the projection of activity of the IE it means additional opportunities in the condition of the formation of some new approaches, strengthening of activity of participation in the already existing federal and regional development programmes of industrial production. However, the fact of priority attention of the state to terms of development of the invested means which do not remove becomes more and more obvious recently, and they also strengthen the responsibility of the IE for its results - for the development of production and the creation of competitive products with the world level of quality. There is a significant amount of examples of positive experience of the effective use of the means of state support which in fact became necessary conditions of economic growth of Russia. Their generalization allows to formulate the key characteristics of the models of realization of policy of diversification at the IE with attraction of financial resources of public financing:

- the existence of obligatory joint financing of the projects (programmes) from the IE at the expense of its own funds which formation in the required quantity is a separate problem of the IE applying for the participation in the programmes of state support;

- the main link of a goal-setting of the policy is a strict binding of the volumes of investment and the results from their use to concrete temporary terms which violation means the state support termination.

The second position concerning the conditions of economic growth in Russia exerting the direct impact on the choice of model of realization of policy of diversification at the IE consists in that the massive external inflow of investments into the Russian economy during a certain period did not provide its high-quality transformation. Therefore there are no reasons to believe that replacement of external sources of financing with internal (state budgetary) ones will lead to any positive result. For the characteristic of the economic development mechanism in the presence of external investors the term "model of the imported growth" was introduced. Concerning the IE it means the domination of external subjects of the economy during forming model of realization of the policy of diversification practically in all the aspects: at a goal-setting, formation of requirements to realization processes, estimation of results. The main problem of the domestic economy which is especially obviously demonstrated in the analysis of the opportunities of attraction of external investments is the weakness of market mechanisms. In Russia not a single of the operating conditions of mature market system which consists of the economic subjects having strong incentives of development and participating in the competition by clear rules is not carried out. Therefore from the positions of the reaching effective mechanisms and models for realization of policy of diversification in the domestic economy the search of 
new forms of public-private partnership, formation of new interactions of the technologically connected IE including belonging to the allied industries of production in the direction of vertical integration in the context of implementation of law regulating strategic planning in scales of the state is very justified

\section{Conclusion}

Considering this matter in the retrospective aspect, we should note that the increase in the speed of introduction of any new products was always present. It was caused by constantly increasing rates of globalization processes, by the reduction of life cycle of the IE products. That resulted in the need to create, introduce and produce new products quicker, than competitors do. In the crisis situations it becomes even more actual, but at the same time the resources for maneuvers, and first of all the financial resources, are significantly reduced. The developed operating conditions at the Russian IE are characterized by the existence of negative dynamics of the with provision of sources of financing both during the implementation of the current activity, and during the implementation of investment projects. It is confirmed by statistical data on change of the coefficients of autonomy and provision of industrial enterprises with own current assets as the values of those coefficients in the end of the third quarter of 2015 made up $40 \%$ and $20.8 \%$ respectively. In this regard the borrowed funds which risks of the use demands the use of complex economic tools at all the stages of the development of new products become the most widespread source of financing of the IE activity which is carrying out "ramp-up" management of projects of diversification in the modern conditions.

\section{References}

1. M.J. Tyre, RES POLICY 1(20), 57-76(1991)

2. C. Terwiesch, R. Bohn, K. Chea, R\&D Management 4(31), 435-451 (2001)

3. F. Carrillo, R.M. Franza, European Journal of Operational Research 2(171), 536-556 (2006)

4. N. Verstina, MATEC Web of Conferences 73, 07022 (2016)

5. E.M. Akimova, D.V. Knyazev, International Journal of Applied Engineering Research 10, 39387-39394 (2015)

6. I. Polyakova, E. Vasilyeva, Procedia Engineering 165, 1380-1387 (2016)

7. E. Krause, D. Krause, Proceedings of the 12th International Design Conference 12, 859-868 (2012)

8. I. Basse, S. Schmitt, T. Gartzen, R. Schmitt Procedia CIRP 20, 93-98 (2014)

9. E. Stein, N. Taskaeva, E. Chibisova, Procedia Engineering 165, 1410-1416 (2016)

10. 4 S. Elstner, D. Krause, Procedia CIRP 20, 20-25 (2014)

11. T.A. Verminskaya, V. Sh. Zinatullin, A.V. Kukhta, I.V. Rubtsov, E. Yu. Chibisova, Almanach of modern science and education 7, 37-39 (2008)

12. G. L. McMillan, Options as a strategic investment. A Comprehensive Analysis of Listed Option Strategies. Second Edition (New York Institute of Finance, New York, 1986)

13. S.Kanyukova, N.Vatin, D.Leybman, T.Sazonova, Procedia Engineering, 165, 1918 1924, (2016), DOI 10.1016/j.proeng.2016.11.942 
14. A. Ehrbar, EVA: the real key to creating value (John Wiley \& Sons, New York, 1998)

15. J.J. Hampton, Financial Decision Making (Prenrice-Hall International Inc., New York, 1989).

16. A. Pimenova, S. Kuzmina, N. Morozova, A. Mottaeva, MATEC Web of Conferences 73, 07018 (2016)

17. I. Polyakova, E. Vasilyeva, Procedia Engineering, 165 (2016)

18. L.V. Nikolova, D.G. Rodionov, A.B. Mottaeva, International Journal of Economics and Financial Issues 6(S3), 1-7 (2016)

19. An.B. Mottaeva, As.B. Mottaeva, International Journal of Applied Engineering Research 1, 10- 23 (2015)

20. An.B. Mottaeva, As.B. Mottaeva, International Journal of Applied Engineering Research 1, 11 - 9 (2016) 